UDC: 17 Seneka L. A

821.134.2.09-2 Kalderon de la Barka P. DOI: https://doi.org/10.18485/hispserb.2019.2.ch12

\author{
Divna Rulić ${ }^{1}$ \\ Universidad de Kragujevac \\ Serbia
}

\title{
EL DESTINO EN LA OBRA DE LUCIO ANNEO SÉNECA Y EN LA DE PEDRO CALDERÓN DE LA BARCA
}

\begin{abstract}
Resumen
Con esta investigación del destino en las obras de Séneca y las de Calderón, nos proponemos parangonar las posturas de estos autores ante uno de los problemas existenciales que sigue llamando la atención de los pensadores. Nuestro objetivo es señalar los puntos comunes y las discrepancias que comparten Séneca y Calderón con respecto al destino y otros problemas existenciales que surjan del análisis y constatar si hubo influencias de Séneca en Calderón o solo coincidencias. Para nuestro propósito tenemos en cuenta el enfoque ético hacia los problemas en cuestión de los autores y el gran interés por la filosofía práctica en la España del Siglo de Oro. Hemos observado grandes semejanzas en la comprensión del destino, la libertad y el albedrío y los recursos que usan sus sabios para protegerse de las consecuencias del destino. Coinciden en la necesidad de sujetarse voluntariamente al destino. Reconocen la importancia de aprender a distinguir los bienes de la fortuna de los bienes verdaderos, a conocer su propia naturaleza. Los dos resaltan que el hombre, ser racional, que dispone de la voluntad y libertad, es responsable de su comportamiento. Difieren en sus actitudes religiosas. En su determinismo fatalista Séneca introduce la providencia
\end{abstract}

${ }^{1}$ rulic.divna@gmail.com 
para justificar los males que ocurren a la gente honrada. Es inseguro respecto a la inmortalidad del alma y la imagen de Dios. Le falta la fe que tiene Calderón en el Dios cristiano. A diferencia de Séneca, Calderón eleva a Dios encima del destino. $\mathrm{Su}$ amor infinito salva el alma de los creyentes arrepentidos. Para Calderón no hay otro destino que Dios. Evidentemente Séneca ejerció influencias en Calderón con sus consejos moralizadores, pero es difícil precisar si de forma directa o indirecta. En nuestra investigación hemos aplicado el método comparativo.

Palabras clave: el destino, la fortuna, el albedrío, Séneca, Calderón.

\section{Introducción}

Unos de los problemas que han ido preocupando a los seres humanos en todas las épocas de la historia de la humanidad ha sido la predestinación. En el fondo del problema de si el hombre ya tiene determinado su futuro o puede crearlo por su propia actuación, o, al menos, lo puede modificar por medio de su comportamiento, está la libertad humana. Como el único ser en la naturaleza dotado de inteligencia, debe sentirse responsable de sus actos, puesto que todo lo que hace, afecta no sólo a él, sino a otros hombres y todo en la naturaleza. Esa responsabilidad que uno debe tener de sus propios actos es "la moral que todo ser humano lleva por dentro" (Cortina apud Carmona Aranzazu 2015: 14-15). En esa posibilidad de elegir entre dos o más opciones valiéndose de la razón, los pensadores y filósofos a través de los siglos buscan la libertad humana. Ahora bien, hay tantos acontecimientos en los que la decisión de actuar de una u otra manera no influye en las repercusiones de los mismos, por lo cual los pensadores y filósofos vuelven a plantearse la cuestión de si el hombre nace predeterminado y si, quizá esa libertad, que a veces el hombre logra alcanzar, también esté prevista por las leyes del destino. Al plantearse la cuestión del destino y de la libertad, cada época trata de dar una respuesta y para ello usa los medios ideológicos que les proporciona su tiempo. En esa eterna polémica de si el ser humano es el creador del propio destino o lo es una fuerza mayor llamada hado, fortuna, los dioses o un solo Dios, Séneca, filósofo romano, recurre a los principios éticos estoicos. También recoge de otras doctrinas todo lo que le conviene para crear el modelo del hombre ideal que forma la parte central de su doctrina. Calderón, dramaturgo español, se atiene, en primer lugar, al dogma cristiano, pero en su interpretación sentimos las influencias de varias corrientes teológicas y filosóficas, entre ellas las de Séneca. A pesar 
de que los separan diecisiete siglos, notamos importantes similitudes entre ellos, discrepancias también, principalmente debido a las diferentes concepciones religiosas, el paganismo de Séneca y el cristianismo de Calderón. Partimos de los puntos comunes a ambos autores: el punto de vista ético de los problemas y su misión pedagógica.

Para realizar dicha tarea, nos apoyaremos en la obra teórica de Séneca: sus Tratados filosóficos, Cartas a Lucilio, Las Cuestiones Naturales. También usaremos sus Tragedias, en las que Séneca, al recrear los mitos antiguos, expone sus pensamientos acerca de problemas existenciales tales como el destino, la fortuna, la libertad y la muerte. Como Calderón no posee una obra teórica, para nuestro propósito nos valdremos solo de su obra dramática, algunas de sus comedias (dramas) y autos sacramentales. ${ }^{2}$ Precisamente los autos sacramentales, con su carácter alegórico, nos facilitarán la comprensión de algunas de sus cuestiones filosóficas que el dramaturgo expone en sus dramas filosóficos y religiosos.

\section{El destino en Séneca}

Cuando hablamos del destino, tenemosque saber qué sobrentiende Séneca con la palabra fatum, en español hado. A la pregunta acerca de qué es el hado, en las Cuestiones Naturales, Séneca dice que es: “(...) la necesidad constante de las cosas y de los hechos, que ningún poder sería bastante a destruir..." (CN II 36; 29). ${ }^{3}$ En el tratado De providencia alude al hado cuando menciona: "Esta inofensiva velocidad obedece al influjo de unas leyes eternas e inmutables, que rigen tanta variedad de cosas como abarca la inmensidad de la tierra y de los mares que gobierna tantísimas estrellas con su hermosa claridad, luciendo según está dispuesto" (De Prov. I, $2 ; 6)^{4}$. En otro lugar del mismo tratado el hado es: "... una larga concatenación de causas que rige la vida privada y pública del hombre" (De Prov. V, 7; 30)5. 0 cuando Séneca enfatiza que: “...nada sucede por

\footnotetext{
${ }^{2}$ La comedia española en los Siglos de Oro es un drama con elementos de comedia y tragedia (Aubrun 1968: 38). El auto sacramental es una obra dramática de carácter alegórico, cuyo tema principal es el misterio de la eucaristía, pero puede tratar otros temas: filosóficos, mitológicos o histórico-legendarios. (Valbuena Prat 1969: 340-344).

${ }^{3}$ Existimo necessitatem rerum omnium actionumque, quam nulla vis rumpat. NQ II, 36, 158.

${ }^{4}$ Hanc inoffensam velocitatem procedere aeternae legis imperio tantum rerum terra marique gestantem, tantum clarissimorum luminum et ex disposito relucentium; De Prov. I, 2. 2.

${ }^{5}(\ldots)$ privata ac publica longus ordo rerum trahit. De Prov.V, 7. 36.
} 
casualidad, como pensamos, sino que todo llega a su debido tiempo, porque tenía que llegar" (De Prov. V, $7 ; 30)^{6}$. A veces Séneca se refiere a las leyes y usa el plural fata, hados en español: "Los hados nos guían, y cuanto a uno le queda por hacer está previsto desde la primera hora de nuestro nacimiento" (De Prov. V, $7 ; 30)^{7}$. Lo entendemos como una ley que sobrentiende muchas leyes en sí.

Para el hado (o hados) de Séneca, usaremos también la palabra destino con ese sentido que tiene para el filósofo romano, la ley inmutable e irrevocable a la que se someten tanto los humanos como los dioses mismos y todo bajo el cielo. ${ }^{8} \mathrm{Al}$ hablar del destino, Séneca va más allá y lo identifica con Dios mismo. ${ }^{9}$ Entonces surge la pregunta "¿qué es Dios?" A la que Séneca responde que es todo lo que es visible y lo que no es visible, que él es todas las cosas, cuida de ellas por dentro y por fuera. Lo considera creador de las leyes del destino, a las que él mismo se somete y las que respeta igual que otros dioses. ${ }^{10}$ En sus Quaestiones Naturales, Séneca identifica el hado con la primera causa de la que dependen todas las demás y, acto seguido añade que cualquier nombre que se le dé, será apropiado si designa la fuerza que reina en el cielo:

¿Quieres llamarle Destino? No te equivocas; de él dependen todos los acontecimientos; en él están las causas de las causas. ¿Quieres llamarle Providencia? Bien le llamas: su providencia vela sobre las necesidades del mundo, para que nada altere su marcha, y realice su ordenado fin. ¿Prefieres llamarle Naturaleza? No errarás: de él ha nacido todo lo que ves; de su aliento vivimos. ¿Quieres llamarlo Mundo? no te engañas; él es todo lo que ves, está todo entero en cada una de sus partes y se sostiene por su propio poder (CN II $45 ; 32)^{11}$.

El problema se plantea cuando Séneca menciona a un Dios y en otros lugares de su obra, que no son pocos, menciona a varios dioses.

\footnotetext{
$\overline{{ }^{6}(. . .)}$ quia non, ut putamus, incidunt cuncta sed veniunt. De Prov.V, 7. 38.

${ }^{7}$ Fata nos ducunt et quantum cuique temporis restat prima nascentium hora disposuit. De Prov. V, 7. 36.

${ }^{8}$ De Prov. V, 8; 38.

${ }^{9}$ Séneca NQ II 45,1; 172.

${ }^{10}$ NQ I, Pref. 13; p. 10. CN I, Pref. 3.

${ }^{11}$ Vis illum fatum vocare, non errabis; hic est ex quo suspensa sunt omnia, causa causarum. Vis illum providentiam dicere, recte dices; est enim cuius consilio huic mundo providetur, Vis illum naturam vocare, non peccabis; hic est ex quo nata sunt omnia, cuius spiritus vivimos. Vis illum vocare mundum, non falleris; ipse enim est hoc quod vides totum, partibus suis inditus, et se sustinens et sua. NQ II 45, 2; 172.
} 
Riesco Terrero (1966: 57) interpreta su referencia a los dioses como distintas formas con las que se manifiesta el poder de un único Dios. También Martín Sánchez (1991: 101) afirma que es probable que Séneca estuviera convencido en la unidad de un solo principio divino. Nosotros, asimismo, nos inclinamos a pensar que con el tiempo se fue encaminando por la línea teística, por lo menos, nos hace creer en eso el fervor con el que profesaba la fe en un único Dios, y las descripciones que hacía de Dios: sumo bien, inteligente, providente, omnipotente, trascendental, paternal, siempre igual. ${ }^{12}$

Para el ideal de su sabio y del ciudadano bueno, Séneca exigía la sumisión a la ley inmutable del hado. Hemos visto que ese hado es, o puede ser el mismo Dios. El Dios de Séneca, sin embargo, no es indiferente e implacable como los dioses paganos tradicionales. Él es inteligente, sabio, bondadoso y con esas características, más aceptable para los ciudadanos hartos de los dioses impasibles ante su destino. Con su preocupación por el hombre parece aproximarse al Dios cristiano, como ha notado Martín Sánchez (1991: 104). No obstante, el estoico romano ahora encara otro problema, cómo explicar y justificar que un Dios tan bueno y poderoso, puede permitir tantas desgracias que ocurren a la gente buena y honrada. El fatalismo del destino que propagaba el estoicismo, Séneca trató de mitigarlo con la providencia y al probar que Dios se preocupaba por el ser humano: "Esto se verá con mayor claridad a través del contenido de esta obra, cuando hayamos probado que la providencia está presente en todas las cosas y que Dios se preocupa por nosotros" (De Prov. I, 5.). ${ }^{13}$ Con esa preocupación paterna de Dios por los hombres y todas las criaturas, Séneca incorpora la providencia en las leyes prescritas que rigen el mundo y explica la necesidad de que alguien guarde el Universo (De Prov. I, $2 ; 2)^{14}$. En su afán por explicar que no hay que dudar, ni quejarse de la providencia cuyos objetivos son buenos, porque "entre los hombres justos y Dios existe una amistad que les une por medio de la virtud" (De Prov. I, 7) ${ }^{15}$, escribe el tratado De Providencia. Al explicar por qué Dios permite que al hombre justo y honesto le sucedan infortunios, Séneca aclara que es también la manera de que Dios endurezca los espíritus

\footnotetext{
${ }^{12}$ El uso de las referencias a los dioses en las tragedias, podríamos explicarlo con fines poéticos.

${ }^{13}$ Hoc commodious in contextu operis redderetur, cum praeesse universis providentiam probaremus et interesse nobis deum. De Prov. I, $1 ; 2$.

${ }^{14}$ Supervacuum est in praesentia ostendere non sine aliquo custode tantum opus stare nec hunc siderum coetum discursumque fortuiti ímpetus esse De Prov. I, $2,2$.

${ }^{15}$ Inter bonos viros ac deos amicitia est conciliante virtute. De Prov. I, 5; 6.
} 
de los que quiere, "así los va preparando para sí" (De Prov. I; 7-8) ${ }^{16}$. A continuación añade que al hombre bueno y sabio no puede ocurrir nada malo, puesto que las cosas opuestas no se mezclan, si es bueno, es bueno, no puede ser malo (De Prov. II, 9) ${ }^{17}$. El hombre justo y sabio cultiva su virtud, no cambia, de modo que puede aguantar todo lo que le depara el hado. ¿Qué es entonces la Providencia, si todo se desenvuelve de acuerdo con las leyes preestablecidas que se deben obedecer? Séneca eleva a Dios encima de todo y de las leyes que él mismo ha dictado, pero insiste en que él mismo las obedece considerándolas perfectas. A la Providencia la considera como "la consecuencia de la suprema sabiduría", como una de las funciones de Dios, igual que el Destino es otra, y aunque parecen incompatibles, uniéndolas como "dos vertientes de la misma realidad" Séneca logra conciliarlas (Martín Sánchez 1991: 106). Por otro lado, se plantea el problema de la existencia del mal, sobre todo mal moral, a pesar de la Providencia y un Dios bondadoso que se preocupa por nosotros. En el monismo materialista Séneca incluye el dualismo moral a fin de sobrepasar "la oposición entre el mal moral y la Providencia" (Riesco Terrero 1966: 62). El origen del cuerpo es materia, mientras que el alma proviene de causa, de la inteligencia, de Dios, principio del bien $(\text { Ep. } 65,1205)^{18}$. El mal moral, las pasiones y vicios provienen de la materia. Mientras que con la razón, chispa divina que lleva por dentro, el hombre puede vencer esa propensión al mal, pero si, a pesar de eso, persiste el mal, es porque "El artífice no puede cambiar la materia: ésta debe resignarse". ${ }^{19}$ En ese dualismo moral algunos críticos ven la maniobra del filósofo moralista para incorporar y justificar la Providencia en su doctrina e incitar a los hombres a ejercitar la virtud (Riesco Terrero 1966: 62-63). La sumisión a los decretos del destino que predica, Séneca la explica arguyendo que los decretos divinos son necesarios para que se mantenga el orden en el Universo y todo funcione bien. A la pregunta de para qué sirven los votos y sacrificios, si todo está predeterminado, Séneca responde que están previstos por el hado, en caso de hacerlos ${ }^{20}$.

Cabe mencionar que en Séneca también hallamos los siguientes conceptos: la fortuna, el azar y la suerte. Con excepción de la fortuna, no nos detendremos en los otros dos términos, por la simple razón de que,

\footnotetext{
${ }^{16}(. .$.$) experitur indurat, sibi illum parat. De Prov.I, 6; 6$.

${ }^{17}$ De Prov. II, $1 ; 6$.

${ }^{18}$ Ep. 65, 2; 3; 444-445.

${ }^{19}$ Non potest artifex mutare materiam; hoc passa est. De Prov. V, 9; 38.

${ }^{20}$ Véase Seneca NQ II 37; 158-160.
} 
el azar y la suerte no tienen un relevante papel en su doctrina puesto que Séneca los rechaza, ya que contradicen su creencia "en un Dios providente, ordenador y bueno sobre todas las cosas" (Montull Calvo 2011: 1). No obstante, Séneca afirma que existe casus, el azar, pues lo encontramos en su obra, por ejemplo, en las epístolas 8 y $91^{21}$. En los ejemplos encontrados, casus una vez lo traducen por fortuna, otra por casualidad. Será porque los efectos del azar y de la fortuna son "imprevisibles" (Martín Sánchez 1991: 98). Sin embargo, en algo se diferencian. Para aclarar la diferencia entre el azar y la fortuna recurriremos a la distinción de Tomás de Aquino: "La fortuna se extiende sólo a las cosas donde la voluntad humana tiene su parte. El azar se extiende a todas las cosas naturales" 22 .

Con la fortuna Séneca se refiere al destino voluble que proporciona y priva a los humanos de los bienes terrenales. A la fortuna le pertenece todo lo que el mundo exterior le brinda al hombre: salud, enfermedades, pobreza, riqueza, fama, honores, etc. Estos bienes o males de la fortuna, como la gente suele llamarlos, son pasajeros mudables e inconstantes, por ende, no merecen ser anhelados por el hombre y no se deben considerar un bien o un mal. Martín Sánchez opina que la fortuna dentro de la filosofía estoica es algo subjetivo, "una comprensión deficiente de la concatenación causal producida por el hado" (1991: 99). No obstante, se puede resistir a la fortuna cultivando la virtud, el bien, que la fortuna no puede dar y por lo tanto no puede quitárselo, pero el hombre puede adquirir con sus propios esfuerzos. ${ }^{23}$

\section{El destino en Calderón}

Calderón usa varios conceptos al referirse al destino del hombre: hado, astrología, fortuna, que en la literatura española del Medievo y el Siglo de Oro no siempre coincidían con su significado. Valbuena Briones traza la trayectoria por la que pasaron esos conceptos partiendo de los clásicos griegos, luego modificados por los estoicos llegaron hasta los medievalistas y de ellos a Calderón. ${ }^{24}$ El hado en Calderón designa las

\footnotetext{
${ }^{21}$ Martín Sánchez (1991: 100) dice que el azar y la suerte designan acontecimientos que suceden cuando se entrecruzan series causales independientes y, que el azar se refiere a lo que acontece "accidentalmente" en los fenómenos naturales y la suerte lo que acontece "accidentalmente" en los fenómenos humanos.

${ }^{22}$ Véase: Santo Tomas apud Martínez Sánchez 1991: 98.

${ }^{23}$ De const. V, 4; 60.

${ }^{24} \mathrm{El}$ concepto del hado, que se relaciona con la visión cósmica y la ley que dirige los procesos del nacimiento, la muerte y la reencarnación de los hombres, proviene del
} 
leyes inevitables que rigen en el universo. Por ser escritas por Dios, las juzga infalibles y perfectas y predica la necesidad de sujetarse a ellas:

\author{
Lo que está determinado \\ Del cielo, y en azul tabla \\ Dios con el dedo escribió \\ De quien son cifras y estampas \\ Tantos papeles azules \\ Que adornan letras doradas, \\ Nunca engaña, nunca miente; [Vs (c) 18]
}

$\mathrm{Su}$ convencimiento en la rectitud de las mismas, la expresa declarando que no mienten, ni engañan, porque son obra de Dios. Calderón en su visión del destino no es fatalista, el determinismo lo supera acudiendo a la teología cristiana. La clave de su visión del hado está en la libertad de actuación del ser humano y en el amor de Dios que puede salvarle el alma, a condición de que haya obrado bien, es decir, llevado una vida virtuosa. Calderón demostró estar bajo un fuerte influjo del ascetismo de los teólogos jesuitas en subordinar la fortuna al libre albedrío y providencia divina. ${ }^{25}$

Otro concepto, la astrología, no siempre gozaba de prestigio, si pensamos en la postura de los teólogos ante ella. El pensamiento que dominaba en aquel tiempo se atenía al catolicismo ortodoxo y se admitía solo la influencia de los astros en el cuerpo, en la naturaleza física. ${ }^{26} \mathrm{Sin}$ embargo, se desacreditaban y prohibían las predicciones de los astrólogos que osaban presagiar el futuro del hombre.

Calderón trata el tema de la astrología en muchas comedias, pero no admite su aplicación para adivinar el futuro del hombre. Como discípulo de los jesuitas, está conforme con la opinión de los teólogos de aquel tiempo, de que los astros pueden predecir solo las inclinaciones futuras del hombre y concede la primacía al libre albedrío y la providencia divina ${ }^{27}$. Nos lo presenta en el ejemplo del rey Basilio de la comedia $L a$ vida es sueño, quien presumiendo de ser docto en astrología, procuró impedir funestas consecuencias del pronóstico sobre el destino de su hijo

\footnotetext{
pensamiento platónico (Valbuena Briones 1965: 10 apud Villanueva 1973: 156-157).

${ }^{25}$ Villanueva enumera, entre otros, a Ribadeneyra, a Rodríguez y a Ignacio de Loyola.

${ }^{26}$ Véase: López 2017: 51-72.

${ }^{27}$ Calderón expone el problema del libre albedrío y la gracia divina conforme a la doctrina molinista. Luis de Molina señala que, para valorar la verdad además de libre albedrío es relevante la razón (Pfandl 1933: 23).
} 
[Vs (c) 18]. Por poco se produce el error trágico que pudo haber llevado a la ruina no solo a los protagonistas, sino a todo el país. ${ }^{28}$ No obstante, Basilio es consciente de la fuerza de libre albedrío sobre los astros:
Porque el hado más esquivo, La inclinación más violenta, El planeta más impío, Sólo el albedrío inclinan, No fuerzan el albedrío. [Vs (c) 5]

Sabe que "un magnánimo varón" puede vencer las estrellas y darle a Segismundo una oportunidad más para salvarse:

Quiero examinar si el cielo,

(...) Se desdice; porque el hombre

Predomina en las estrellas

Esto quiero examinar. [Vs (c) 6]

Bandera (1976: 728-729) indica la relación que hay entre el carácter del horóscopo de Segismundo y el modo de leerlo de Basilio. Basilio en el horóscopo de su hijo vio "un monstruo", pero no vio que ese monstruo podía ser él al privar a Segismundo de la libertad. Bandera comenta que el caos en el drama se produce por la ceguera de los personajes ante sí mismos. Basilio no nota que la violencia de Segismundo es un "reflejo de su propia violencia" (Bandera 1976: 742) y que cuando se rebela el pueblo, solo sigue el ejemplo de Basilio, rebelado contra su hijo. Segismundo sabe de sí mismo de la imagen que otros dan de él, así que su violencia es "imitación" de lo que ha sufrido. Esta ceguera de los personajes, en opinión de Bandera, los encadena a su propio destino. Cuando Segismundo empieza a ver las cosas con sus propios ojos, empieza a discurrir y corregir su conducta, es cuando se evita el funesto desenlace del presagio. Merece mencionar la objeción de Parker (apud Braga 2007: $15)$ que "todas las profecías astrológicas se cumplen infaliblemente en las obras de Calderón de la forma que fueron predichas". Braga (2007: 16) se pone de acuerdo con él y trata de dar la respuesta basando su explicación en el criterio de determinar quién hace la profecía, un agente natural, sobrenatural o humano. Partiendo de eso, Braga (2007: 25) constata que,

\footnotetext{
${ }^{28}$ La opinión general de los críticos es que la España del Siglo de Oro no hizo ninguna contribución notable a la tragedia. Tampoco a Calderón se le considera un escritor trágico por el desenlace piadoso de sus obras. Véase: Herbert Müller. "The Spirit of Tragedy". Apud Alexander A. Parker 1976: 359.
} 
como el hombre falla al interpretar una profecía, luego participa en su cumplimiento inconsciente de ello. Calderón demuestra en varios casos que los que creen en las profecías y las temen con su comportamiento provocan el final trágico. Por ejemplo, Clarín huyendo de la muerte, la encuentra y exclama:

Pues no hay seguro camino

A la fuerza del destino

Y a la inclemencia del hado. [Vs(a)17]

Sus palabras, "mirad que vais a morir, si está de Dios que muráis" (Vs (c) 18), de repente hacen consciente a Basilio de su propio error. En su intento de impedir que se cumpla el presagio, Basilio se ha enfrentado a las cosas de Dios, privando a Segismundo del derecho natural, de la libertad (Andueza 2000: 90). Con ello manifestó su ignorancia, aún más, provocó el cumplimiento del destino causando el efecto contrario. Calderón nos recuerda que los decretos divinos son inescrutables para el ser humano y meterse en ellos es engreírse, ir contra la voluntad de Dios, lo mismo que hace el demonio. El envanecimiento es el pecado capital. Lo que sí puede el hombre es dominar su naturaleza instintiva con su voluntad y libertad interior ${ }^{29}$. En este sentido, Calderón amonesta a los hombres que se sujeten al destino, que no se metan en las cosas divinas, sino que se esfuercen con las potencias que tienen en crear su propio destino con sus obras.

Además del hado, Calderón usa el concepto de fortuna. Meléndez alega que el dramaturgo se refiere a la fortuna en dos sentidos, uno más profano y otro más religioso. En el sentido profano resalta su carácter mudable y veleidoso, mientras que en el religioso "responde a una lógica superior al entendimiento humano" (Meléndez 2008: 398). La imagen de fortuna como algo caprichoso e imprevisible, y por eso temible, corresponde al primer punto de vista ${ }^{30}$. Esta visión de la fortuna la tiene la mayoría de los personajes en sus obras. La descripción que Calderón da de ella, evidencia de la mejor manera cuáles son sus cualidades:

\footnotetext{
${ }^{29}$ En su concepción de la libertad y la predestinación fue influenciado por San Agustín (Valbuena Prat 1969: 545-555).

${ }^{30}$ Meléndez (2008: 323) interpreta el primer punto de vista con dos modos distintos, uno como algo temible e incontrolable y otro como "poco más que simple superstición". Para nosotros, el "primer modo" de su primer punto de vista corresponde a lo que Calderón llama hado, mientras que el "otro modo" corresponde a su concepto de fortuna, una deidad veleidosa en la que cree la gente supersticiosa, esperando de ella el bien o el mal en el sentido superficial de bienes terrenales.
} 
Que esa diosa que en altares Vivió idolatrada un tiempo, A quien dieron ignorantes Los hombres bultos de bronce Sobre las columnas de jaspe, Es de aspecto tan confuso De tan dudoso semblante, De tan engañoso trato Y de condición tan fácil, Que, a quien la mira, parece Que diversos rostros hace,
Como el girasol que muestra Verdes y rojos celajes. (...) Y ya sé que su hermosura Es maravilla, que nace $\mathrm{Al}$ alba, y muere a la noche, Como efímera fragrante. Y siendo así que he llegado Yo mismo a desengañarme, Aun prevenido la temo Esperando cada instante El golpe (Smb. p. 25)

La versatilidad de la fortuna Calderón frecuentemente la presenta mediante una rueda que gira velozmente, o a través de un mar agitado que juega con un barco, o de las tempestades, imágenes que encontramos en Séneca también ${ }^{31}$.

La otra visión, según Meléndez Terrero (2008: 329), es realmente el mensaje que Calderón nos transfiere, que la fortuna no es lo que les parece a los personajes, veleidosa e inconstante, sino que se debe contemplar desde la vertiente de los efectos beneficiosos o nefastos que, en realidad, son la consecuencia de la voluntad de Dios contenta o descontenta con la actuación del hombre en la respectiva situación. Y como concluye Meléndez, lo que los personajes al principio toman por fortuna, deidad voluble, son las repercusiones de la aprobación o rechazo que hace Dios ante la determinada conducta del hombre. Es como Dios premia y castiga a los seres humanos. Calderón sugiere que el hombre con su buena conducta puede moderar los efectos del juicio de Dios. El mismo título del auto sacramental No hay más Fortuna que Dios, nos transmite el mensaje de que la Fortuna es una deidad inventada, que solo hay Dios. Su mensaje es que la religión cristiana no deja al hombre a los dioses caprichosos, sino que le da la oportunidad para merecer la salvación del alma. En este sentido Calderón nos da una visión positiva, optimista, la cual incluye la participación del hombre en la creación de su futuro disponiendo de las potencias necesarias. Insiste en que la aceptación de los bienes de la fortuna es su sujeción voluntaria a Dios.

\footnotetext{
${ }^{31}$ Calderón: Smb 25. EC: 201. Seneca: OED 249-255; 448. Séneca: ED 22.
} 


\section{La comparación de las actitudes de Séneca y Calderón ante el destino}

Hay muchos puntos equiparables entre los pensamientos de Séneca y los pensamientos de Calderón sobre el destino. Son parecidos en cuanto a los instrumentos y modos de luchar contra él. Los dos autores ponen de relieve la importancia de conocer la naturaleza del bien y del mal, indispensable para saber escoger el bien verdadero. ${ }^{32}$ Los bienes de la fortuna, o sea los bienes terrenales no son ni buenos ni malos en opinión de los dos autores. De si van a ser buenos o malos, depende de cómo el hombre se sirva de ellos. El mismo hecho de que los proporciona la fortuna, ya de por sí habla de su inconstancia y transitoriedad, por lo que los dos autores les niegan la importancia y advierten sobre los peligros en caso de anhelarlos. En la epístola 98, Séneca a los bienes de la fortuna los llama mortales, en contraste con el verdadero bien, la virtud, que no cambia y no perece, "el único bien inmortal que alcanzan los mortales" (Ep. 98, 1481). ${ }^{33}$ Saber diferenciarlos es aptitud del hombre sabio. Séneca el papel principal en la dilucidación de ellos, lo ve en la naturaleza racional del hombre, la cual el hombre comparte con Dios, a quien Séneca también llama Razón ${ }^{34}$. Si la razón es común al hombre y a Dios, es lo que los aproxima, "lo inmortal en un mortal". Como la razón es una condición indispensable para la existencia del bien, entonces resulta que la ausencia del razonamiento es un mal. En la epístola 66, Séneca explica la necesidad de que el hombre use la razón, que "la razón sabe juzgar de los bienes y males, no aprecia cosas ajenas y externas, y en cuanto a aquellas que no son buenas ni malas, las tiene en muy poco" (Ep. 66, $1221)^{35}$. Pues el lugar de la razón es el alma, igual que el lugar de la virtud. Si es así, no hay virtud sin razón, ni bien sin virtud. Como no hay bien sin conocimiento de lo que el mismo presenta, el bien es saber, dice Séneca y añade, entonces el mal es la ignorancia ${ }^{36}$. En la concepción determinista estoica, el sometimiento del sabio al implacable destino no dejaba mucho lugar a la libertad de actuación. Sin embargo, Séneca busca la manera de salvar la libertad, y con ella dar más sentido a su llamada a sujetarse al hado. Séneca recurre al fortalecimiento del alma, con el que el sabio logra

\footnotetext{
${ }^{32}$ Calderón incluso tiene una comedia que se titula Saber del bien y del mal.

${ }^{33}$ (...) hoc unum contingit inmortale mortalibus. Ep. 98, 9; 122-124.

${ }^{34}$ NQ I, Pref. 15; 12. CN I Pref. 3.

${ }^{35}$ Ratio ergo arbitra est bonorum ac malorum aliena et externa pro vilibus habet et ea, quae neque bona sunt neque (...) mala. Ep. 66, 35; 24.

${ }^{36}$ Séneca: Ep. 31, 1102; Ep. 31, 6; 224.
} 
resistir a todos los males, que no puede evitar, pero puede soportarlos con tranquilidad y valentía. La libertad no es guerrear para él, sino aguantar orgullosamente: "La libertad no es no tolerar nada (...) la libertad consiste en saber enfrentar nuestro ánimo contra las injurias y prepararlo de tal manera que solamente pueda recibir de él cosas agradables." ${ }^{\prime 3}$ La libertad es usar la razón para controlar los movimientos del cuerpo y alma. Es fuerza racional, dice Martín Sánchez (1965: 109) porque mediante el razonamiento el sabio reconoce el valor de ser libre y lo consigue mediante la voluntad. La voluntad estimula la razón a actuar. Sin voluntad no hay libertad. Cuando habla de la libertad, se refiere a la libertad interior, la libertad del alma. La libertad consiste en la independencia en el obrar (Elordoy 1972: 268-269). Una de las formas de demostrar la libertad para Séneca, es poder abandonar esta vida en situaciones extremas. Si bien no aprueba el suicidio por cobardía, hay casos cuando permite al sabio que recurra al suicidio.$^{38}$ En eso discrepa por completo de Calderón, quien como buen cristiano no acepta el suicidio. Para entender el destino es preciso entender la visión de la muerte de ambos autores. ${ }^{39}$

Séneca y Calderón coinciden en su modo de reconocer el bien y el mal en el sentido exacto de la palabra. Calderón, también resalta la importancia del razonamiento en la adquisición de los conocimientos necesarios para discernir el bien exterior del interior y con ello decidir su destino ${ }^{40}$. Los dos identifican el bien con la virtud y el mal con los vicios. Ese saber hace posible dirigirse por el camino recto y no perder el tiempo en cosas superfluas que acarrea la fortuna. La importancia de la actividad racional, Calderón la presenta en sus autos con el personaje Entendimiento, la más importante potencia que recibe el alma ${ }^{41}$. Otras dos son La Voluntad y La Memoria. Frutos (1976: 491-499) destaca el origen divino y la función de conocer lo natural y lo sobrenatural del Entendimiento, pero subraya que no siempre llega a comprender todo,

\footnotetext{
${ }^{37}$ Non est autem libertas nihil pati, fallimur; libertas est animum superponere iniuriis et eum facere se, ex quo solo sibi gaudenda veniant... Véase De const. 19; 224. De const. 19.3; 102.

${ }^{38}$ Véase: De prov. VI, 6; 44. De prov. VI, 36.

${ }^{39}$ Véase: Rulić Divna 2014: 87-105.

${ }^{40}$ Para su visión de la razón Calderón se inspiró en el tomismo de Francisco Suárez. Valbuena Prat 1969: 545-555.

${ }^{41}$ Frutos (1976: 491-498) sitúa al Entendimiento entre las facultades intelectivas como el Ingenio, el Pensamiento, la Razón natural y el Discurso, pero para nuestro objetivo, nos detendremos solo en el Entendimiento. No son sinónimos, pero pueden coincidir en algunas funciones, la idea que expresan solo se entiende en contexto de cada obra.
} 
entonces acude a la $\mathrm{Fe}$, porque su poder cognitivo no puede alcanzar los secretos divinos. El racionalismo de Calderón, Frutos lo entiende como estimación inteligente de lo mejor, como algo razonable. El alejamiento del Entendimiento representa el estado sin razonamiento, en el que al héroe le dominan las pasiones, estado de necedad y desconocimiento que lleva al cumplimiento del oráculo y sus consecuencias funestas. Tal es el estado de Segismundo cuando por poco mata a su ayo Clotaldo o del Hombre en el auto del mismo nombre, cuando arroja al Entendimiento por haberle molestado con sus prudentes consejos ${ }^{42}$. Caso comparable con el Hércules de Séneca en la Locura de Hércules. El invencible héroe, quien "ha sujetado a la tierra y el mar embravecido" (Hf III 1945: 49) ${ }^{43}$ en lugar de lavar las manos con "sagrada expiación" (op. cit. 49), en un arrebato de locura, se ensoberbece y se subleva contra el cielo:

Los reinos infernales han probado mi fuerza; el cielo sigue aún intacto: ¡he aquí un trabajo digno de Alcides! Yo me elevaré a los altos espacios del universo; a mi padre, que me promete lugar entre los astros. ¿Y si me dijera que no? La tierra entera no puede contener a Hércules, y ya al fin vuelve hacia las alturas. (Hf III, 49)

No poder refrenar la soberbia, dejarse llevar por la ira, es la ceguera causada por las pasiones, es el mal para Séneca. Hércules mata a su propia familia obcecado por la soberbia y la ira. Al recuperar el razonamiento, Hércules reconoce la culpa por haber asesinado a su mujer e hijos. Horrorizado por su monstruosidad, desea quitarse la vida, pero no es digno de un héroe matarse por debilidad. Haber reprimido su dolor y obedecido a su padre lo considera una hazaña digna de contarse entre los trabajos de Hércules ${ }^{44}$. Sin embargo, la tragedia no se pudo evitar. Por el contrario, en Calderón se evita la tragedia. Segismundo asesina a un criado, por poco mata a Clotaldo y amenaza con destronar a su padre. Cuando empieza a razonar, corrige su conducta, decide obrar con cordura. Basilio reconoce su error y se entrega a su hijo exclamando:

Cumpla el hado su homenaje, Cumpla el cielo su palabra. [Vs (c)18]

\footnotetext{
${ }^{42}$ Véase: [Vs (c) 10]; [Vs (a), 432].

${ }^{43}$ HF III 955-960, 84; Hf III 918-219, 80.

${ }^{44}$ Séneca: Hf IV, 62. HF IV 1315-1316; 116.
} 
En efecto, el hado se cumple, pero no las consecuencias desastrosas. Con esta prudente actuación, Segismundo evita el trágico final. Sustituye a Basilio en el trono, pero sin violencia. En la tirada de Segismundo postrado ante su padre y rey, el mensaje de Calderón muestra que mediante la violencia y la agresividad no se puede con el destino ya que causa el efecto contrario:

La fortuna no se vence

Con injusticia y venganza,

Porque antes se incita más; [Vs (c)18]

Los autores con el saber del bien y del mal en "la lucha con el destino" sobrentienden el conocimiento de sí mismo, de su ser mortal. Con esos conocimientos ambos tratan de concienciar al hombre y devolverlo al camino recto, Calderón recordándole que "polvo fuiste, polvo eres, y polvo serás" ${ }^{45}$, Séneca con palabras del Coro que el hombre al morir, yacerá donde "...yacen los que no han nacido" iguala el lugar antes de haber nacido con el de la muerte (Troy 86) ${ }^{46}$. Ambos coinciden en la idea de que después de la muerte no queda nada del cuerpo, pero no en cuanto a lo que sucede al alma. Para Calderón, la salvación del alma. Para Séneca, incertidumbre, tal vez para el sabio la salvación del alma, por lo menos hasta la conflagración del Universo.

La sumisión a lo que nos trae el destino se refleja ya en la idea de la vida como comedia que aparece en Séneca y en Calderón. Uno de los temas que plantea la idea del mundo como teatro, relacionada con el destino, es el reparto de los papeles por el Autor. El papel no se puede elegir porque el Autor le da a cada uno lo que le conviene, solo se requiere que lo desempeñen bien. Se vuelve a repetir la idea de que hay que aceptar lo que nos trae el hado o Dios, luego nosotros lo hacemos bueno o malo ${ }^{47}$. Que no importa qué papel o profesión obtenga uno, ofrece asimismo el auto No hay más Fortuna que Dios, donde Calderón utiliza una imagen popular del árbol lleno de insignias que la Justicia, por orden de Dios, reparte a los hombres, advirtiendo que cada papel es bueno, que todos son iguales y que en cada papel se gana, si se actúa bien:

\footnotetext{
${ }^{45}$ Calderón: Vs (a) 429.

${ }^{46}$ Véase ejemplos de lo que queda del hombre después de la muerte en Séneca: Tro 397; 156. En HE 218. HO 1758-1760; 324.

${ }^{47}$ Valbuena Prat (1968: 547) cita a Séneca y a Epícteto (1966: 496) como posibles fuentes para el Gtm de Calderón. Sin embargo, Vilanova (1950: 153-161) alega la posibilidad de la influencia de los dos autores por las sátiras de Luciano de Samósata y la difusión por las obras de Erasmo.
} 
Pues ningún estado es malo como el hombre en él sea bueno; (Nfd 8)

Lo mismo pasa con la vida y la muerte que de por sí no son buenas ni malas, sino que nosotros las hacemos buenas o malas. La respuesta a la pregunta "¿Quién soy, qué seré, o qué fui?" ${ }^{48}$, el inicio del discurrir, puede conducir a la "victoria sobre sí mismo"49 la mayor que el hombre puede conseguir, reprimiendo la fiera que lleva él por dentro ${ }^{50}$. Esa "fiera" son los vicios y las pasiones, el mal, el Demonio en Calderón o la Furia en Séneca, los dos identificados con la ignorancia ${ }^{51}$.

\section{Conclusión}

Séneca y Calderón tienen, en buena parte, posturas idénticas respecto a la comprensión del destino como los decretos determinados por una fuerza superior o Dios, cuyo papel es mantener el orden en el Universo. Por consiguiente, consideran que es la obligación moral del hombre someterse a ello, aceptar lo que les traigan con serenidad porque ningún bien que nos proporcionan es ni bueno ni malo, que sea bueno o malo lo hacemos nosotros con nuestro obrar, para lo que disponemos de la razón, la libertad y la voluntad. En la sumisión a ellos ambos ven el deber natural del hombre. Coinciden en los medios que el hombre sabio usa para enfrentarse a los efectos del destino. Los dos consideran que, para encarar el hado, es preciso poseer el saber del bien y del mal, que sobrentiende el conocimiento de su propia naturaleza. Séneca y Calderón están de acuerdo en que el destino del cuerpo es sucumbir, descomponerse, pero cuando se trata del destino del alma, notamos discrepancias, que provienen de sus diferentes concepciones de Dios y de la inmortalidad del alma. En Calderón, la fuerte fe cristiana en el misericordioso Dios permite el arrepentimiento hasta el último momento de la vida y con la gracia de Dios, la salvación del alma. Sin embargo, Séneca manifiesta incoherencias respecto a la creencia en varios o en un único Dios, respecto a lo que es Dios, "un dios,... una razón incorpórea,...un espíritu divino... destino o una serie inmutable de causas", en resumen un

\footnotetext{
${ }^{48}$ Calderón: Vs (a), 427.

${ }^{49}$ Véase: Séneca Ep. 113, 31; 298. Ep. 113, 1562. Calderón Vs (c) 18.

${ }^{50}$ Véase: Calderón: Vs (c), 18. Vs. (a), 428. Seneca: Ep. 113, 31; 298. Ep. 113, 31; 1562.

${ }^{51}$ Véase: Calderón Nfd 4-8. Séneca Thy 32; p. 95. Tiet, 108.
} 
misterio (Ad Helv. 8, 3; 584)..$^{52}$ Con el tiempo, suaviza y humaniza un poco la visión de Dios dándole atributos de bondadoso, paternal, providente. Titubea también cuando habla de su concepción de la muerte: "es el fin o el tránsito" ${ }^{53}$. Por un lado, niega que quede algo después de la muerte, y por otro, vislumbra la esperanza y abre la posibilidad de la salvación del alma del sabio, a condición de llevar una vida virtuosa. Tanto Séneca como Calderón reconocen la virtud como el único bien, que mora en el alma, mientras que el mal lo ven en los vicios y pasiones, pero están de acuerdo en que las virtudes y los vicios son el resultado de la actuación buena o mala del hombre y no de una fuerza externa. Los protagonistas en las tragedias de Séneca son posibles portadores del destino trágico con respecto a los crímenes cometidos por sus antepasados. El hado se cumple siempre con consecuencias trágicas, pero no por predestinación, sino porque los héroes se dejan llevar por las pasiones y cometen crímenes. Calderón también menciona que el hombre nace con el pecado, pero lo lava con el agua bautismal, pero queda la posibilidad de volver a cometerlo. Para Séneca, el hado obra sobre los hombres pecaminosos, por lo que a una catástrofe obligatoriamente antecede la culpa personal. En Calderón, el hado se cumple en mayoría de los casos, pero son muy pocos los casos de efectos trágicos. Solo los protagonistas que hasta el final no reconocen haber pecado, sino dejan ser arrastrados por los vicios, sufren el final trágico, como el rey Baltasar. ${ }^{54}$

Séneca admite la fortuna solo dentro del hado. Calderón, por su parte, no admite otra fortuna que Dios.

El uso del libre albedrío en la elección del bien o el mal lo encontramos en Séneca y en Calderón. La libertad volitiva de la que disponen, determina su destino. Séneca refuerza su doctrina moralizadora con la libertad humana, incompatible con las leyes inexorables, señalando que Dios no es menos poderoso y menos libre por respetar las leyes del destino. Agrega que la libertad del hombre se refleja en la aceptación voluntaria del destino. La libertad a la que se refieren Séneca y Calderón es interior, la que depende de nuestra voluntad. En ella nada puede influir, pero puede incitar a la gente a obrar bien, a superar las consecuencias del destino. En su destino inflexible, Séneca introduce la Providencia para demostrar que Dios se preocupa por el hombre y lo expone a las duras

\footnotetext{
${ }^{52}$ (...) sive ille deus est... sive incorporalis ratio, ....sive divinus spiritus, ...sive fatum et immutabilis causarum... Ad Helv. 8, 3; 440.

${ }^{53}$ Ep. 65 24, 458. Ep. 65, 1211.

${ }^{54}$ Calderón CrB 125.
} 
pruebas del destino para fortalecer su ánimo. La Providencia y el Destino resultan ser dos vertientes del mismo Dios. El Dios de Séneca no es indiferente ante las desgracias de los hombres, sino que guía a los hombres por el camino de la virtud. Con ello intenta explicar las desgracias que sobrevienen hasta a los hombres sabios con el fin de hacerlos ejercitar la virtud.

Para Calderón, sin embargo, no hay titubeos ni vacilaciones en cuanto a Dios. Existe solo un Dios único, sumo bien, misericordioso, que puede salvar al hombre arrepentido antes de la muerte de las repercusiones del destino. Cuando habla de la salvación, Calderón, piensa en la salvación del alma, como la única parte inmortal en el ser humano. Para él, el único destino es el destino del alma. La salvación que espera el hombre de Calderón, en la mayoría de los casos se realiza después de la muerte. Son menos los ejemplos de los héroes que se salvan ya en esta vida, como Segismundo. Logran "vencer" el destino los que han logrado dominar sus pasiones. La salvación en los autos sigue después de que uno se haya arrepentido y pedido ayuda de la Gracia divina, como en caso de Cipriano ${ }^{55}$. El hombre sabio de Calderón lucha contra los golpes del destino con su fuerte fe en Dios y su infinito Amor, que ha enviado a su Hijo a la Cruz para redimir la humanidad. La salvación se logra administrando el sacramento de la sagrada eucaristía, que es una redención continuada ${ }^{56}$.

Son obvias las influencias de Séneca en Calderón en cuanto a los consejos éticos prácticos para el fortalecimiento del alma, admisión del destino, cultivo de la virtud y de la libertad interior. No obstante, es difícil discernir cuáles influyeron en Calderón por medio de otros autores y cuáles directamente. El hecho es que Séneca con su doctrina moralizadora práctica inspiraba a los que posteriormente divulgarían el cristianismo.

\footnotetext{
$\overline{{ }^{55} \text { Calderón Mp } 190 .}$

${ }^{56}$ Véase: Marcos Villanueva 1973: 155.
} 


\section{Abreviaturas de las obras citadas de Séneca}

\begin{tabular}{|c|c|c|c|}
\hline Ad Marc. & De Consolatione ad Marciam & Cons.a Marc. & Consolación a Marcia \\
\hline Ad Helv. & De Consolatione ad Helviam & Cons. A Helv. & Consolación a Helvia \\
\hline De Benf. & De Beneficiis & De Benf. & De Beneficios \\
\hline De Brev.Vit. & De Brevitate vitae & De Brev.Vid. & De la brevedad de la vida \\
\hline De Cons.sap. & De Constantia sapientis & De Cons.sab & De la constancia del sabio \\
\hline De Prov. & De providentia & De Prov. & De Providencia \\
\hline De Vit.bea. & De vita beata & De Vit.bea. & De la vida bienaventurada \\
\hline QN & Quaestiones naturales & $\mathrm{CN}$ & Cuestiones naturales \\
\hline
\end{tabular}

\section{Tragedias}

$\begin{array}{llll}\text { HF } & \text { Hercules furens } & \text { Hf } & \text { La locura de Hércules } \\ \text { HO } & \text { Hercules Oeteus } & \text { HE } & \text { Hércules en el monte de Eta } \\ \text { Thy } & \text { Thyestes } & \text { Ties } & \text { Tiestes } \\ \text { Tro } & \text { Troades } & \text { Troy } & \text { Troyanas } \\ \text { OED } & \text { Oedipus } & \text { ED } & \text { Edipo }\end{array}$

De las obras citadas de Calderón: autos sacramentales y comedias

$\begin{array}{llll}\text { Vs } & \text { La vida es sueño } & \text { (a) } & \text { (c) } \\ \text { CrB } & \text { La cena del rey Baltasar } & \text { ( a ) } & \\ \text { NFD } & \text { No hay más fortuna que Dios } & \text { (a) } & \\ \text { Gtm } & \text { El gran teatro del mundo } & \text { ( a ) } & \text { (c) } \\ \text { Mp } & \text { El Mágico prodigioso } & & \text { (c) } \\ \text { Pc } & \text { El Príncipe constante } & & \\ \text { EC } & \text { Los encantos de la culpa } & \text { (a) } & \text { (c) } \\ \text { Smb } & \text { Saber del mal y del bien } & & \end{array}$

\section{FUENTES}

Calderón de la Barca, Pedro. Comedias. Tomo VII, Madrid: Atlas, 1944. Impreso.

Calderón de la Barca, Pedro. Obras. Tomo II, Madrid: Atlas, 1945. Impreso.

Calderón de la Barca, Pedro. Autos sacramentales. Tomo LXVIII, Madrid: Atlas, 1952. Impreso.

Calderón de la Barca, Pedro. Autos sacramentales. Barcelona: Ramón Sopena, S.A., 1972. Impreso.

Calderón de la Barca, Pedro. No hay más Fortuna que Dios. Ed. Ignacio Arrellano, Pamplona-Kassel: Universidad de NavarraReichenberger, 2013.

<http://dadun.unav.edu/bitstream/10171/37444/1/81_ fortuna_dios_auto.pdf> Web. 05 Sep. 2018. 
Séneca, Lucio Anneo. Tragedias. Ed. de P. A. Martín Robles, 2 vols, Biblioteca Clásica tomos XV y XVI, Madrid: Librería y Casa Editorial Hernando, S.A., 1945. Impreso.

Seneca, Lucius Anneus. Epistulae Morales. Ed. William Heinemann LTD. Trans. by R. M. Gimmere, 3 vols, London: The Loeb Classical Library, 1967. Print.

Seneca, Lucius Anneus. Tragedies. Ed. William Heinemann LTD. Trans. by F. J. Miller, 2 vols, London: The Loeb Classical Library, 1968. Print. Seneca, Lucius Anneus. Naturales Quaestiones. Ed. William Heinemann LTD, Trans. by Thomas H Corcoran, 2 vols, London: The Loeb Classical Library, 1971. Print.

Seneca, Lucius Anneus. Moral Essays. Ed. William Heinemann LTD. Trans. by J. W. Basore, 3 vols, London: The Loeb Classical Library, 1970. Print.

Séneca, Lucio Anneo. "Consolación a Marcia". Tratados Filosóficos, Tragedias, Epístolas Morales. Traducción de J. Azagra, Madrid: EDAF, 1972: 617-676. Impreso.

Séneca, Lucio Anneo. "Epístolas Morales". Tratados Filosóficos, Tragedias, Epístolas Morales. Traducción de J. Azagra, Madrid: EDAF, 1972: Ep. 116. p. 1579. Impreso.

Séneca, Lucio Anneo. Cuestiones naturales. Traducido por Francisco Navarro y Calvo. Madrid, 1884. Biblioteca Virtual Miguel de Cervantes, Alicante, 1999.

<http://www.cervantesvirtual.com/obra/cuestiones-naturales--0/> Web. 03 Mar. 2019.

\section{BIBLIOGRAFÍA}

Andueza, María. "Libertad /destino en La vida es sueño de Calderón de la Barca”. Revista de la Universidad de México. Núm. 591-592, AbrilMayo (2000): 88-95.

<http://www.revistadelauniversidad.unam.mx/ojs_rum/files/ journals/1/articles/15/public/15045-20443-1-PB.pdf> Web. 09 Aug. 2018.

Bandera, Cesáreo. "El 'confuso abismo' de La vida es sueño". Manuel Durán \& Roberto Echevarría González. Calderón y la crítica: Historia y antología. Tomo II, 1976: 723-746. Impreso.

Braga, Corin. "Calderón de la Barca y el conflicto de paradigmas en la Edad de oro (I)". Rivista di filosofía on-line. Año II, Núm. 4. Noviembre 
(2007). <http://www.metabasis.it/articoli/4/4_Braga.pdf> Web. 08 Feb. 2018.

Carmona Aranzazu, Iván Darío. "Libertad o destino: El laberinto de la condición humana”. Medellín-Colombia Escritos. Vol. 23, Núm. 50. Enero-Junio (2015): 13-21. <https://revistas.upb.edu.co/index. php/escritos/index > Web. 08 Mar. 2019.

Cilveti, Ángel. El demonio en el teatro de Calderón. Madrid: Albatros, 1977: 53-54. Impreso.

Elordoy, Eleuterio. El Estoicismo, 2 vols, Madrid: Gredos, 1972. Impreso. Epictetus. The discourses as reported by Arrian, Manual and fragments. Vol. II, London: Loeb Classical Library, 1966. Impreso.

Frutos Cortés, Eugenio. "La filosofía en sus autos sacramentales: las potencias del alma y el libre albedrío". Manuel Duran \& Roberto Echevarría González. Calderón y la crítica: Historia y antología. Tomo II, 1976: 481-540. Impreso.

López Facundo, Hernán. "Pedro Mexía y la astrología en el siglo de oro español”. Universidad Buenos Aires: Melancolía, 2 (1917): 51-77. <file:///C:/Users/Divna/Downloads/18-86-1-PB\%20(1).pdf > Web. 04 Mar. 2019.

Marcos Villanueva, Balbino. La Ascética de los Jesuitas en los Autos Sacramentales de Calderón. Bilbao: Universidad de Deusto, 1973. Impreso.

Martín Sánchez, María Angelita Fátima. "La inmortalidad del sabio en Séneca". Helmántica, 35\#106-108. 1984: 81-89. Impreso.

<https://summa.upsa.es/viewer.vm?id=3132\&amp;view=main \&amp;lang=en> Web. 30 Aug. 2018.

Martín Sánchez, María Angelita Fátima. "Fatum i Providentia en Séneca". TAULA, quaderns de pensament (UIB) 16, (1991).

<http://ibdigital.uib.es/greenstone/collect/taula/index/assoc/ Taula_19/91v16p09.dir/Taula 1991v16p091.pdf> Web. 27 Aug. 2018.

Meléndez Terrero, María del Carmen. Aproximación al pensamiento político en la obra de Calderón. Tesis doctoral. Departamento de Literatura y Teoría de la Literatura, Facultad de filología, Universidad Nacional de Educación a Distancia, 2008. http:// espacio.uned.es/fez/eserv/tesisuned:FilologiaMcmelendez/ Documento.pdf> Web. 05 Mar. 2019.

Menéndez y Pelayo, Marcelino. "Dramas trágicos". Manuel Durán \& Roberto Echevarría González. Calderón y la crítica: Historia y antología. Madrid: Gredos, 1976: 127-165. Impreso. 
Montull Calvo, Tomás. “Hado, Destino, Providencia en Séneca”, 05.03.2011 <http://teologahumana.blogspot.com/2011/03/hado-destinoprovidencia-en seneca_05.html> Web. 08 Sep. 2018.

Müller, Herbert Joseph. "The Spirit of Tragedy". Alexander A. Parker. "Hacia una definición de la tragedia calderoniana", publicado en: Manuel Durán \& Roberto González Echevarría. Calderón y la crítica: historia y antología. Tomo II. Madrid: Gredos, 1976: 359387. Impreso.

Palacios, Leopoldo Eulogio. Don Quijote y La vida es sueño. Madrid: Rialp, 1960: 31-88. Impreso.

Pfandl, Ludwig. Historia de la literatura nacional española en la Edad de Oro. Traducción por R. Balaguer. Barcelona: Juan Gili, 1933. Impreso.

Riesco Terrero, José. "Dios en la moral de Séneca”. Helmántica. Revistas UPSA. Vol. 17; Núm. 52-54 (1966): 49-75.

<https://summa.upsa.es/high.raw?id=0000002697\&name $=$ 00000001.original.pdf> Web. 15 Jul. 2018.

Rulić, Divna. „Zlo kod Lucija Aneja Seneke i Pedra Kalderona de la Barke“, ZENIT, Magazin za umetnost, nauku i filosofiju, God. V, Broj 11, jesen (2010): 50-59. Štampano.

Rulić, Divna. "La actitud ante la muerte del ideal del sabio de Lucio Aenneo Séneca y el hombre sabio de Calderón de la Barca". Anđelka Pejović et al. (Eds.). Estudios Hispánicos en la cultura y ciencia serbia (Actas de la Primera conferencia nacional de hispanistas serbios). Kragujevac: Facultad de Filología y Artes de Kragujevac, 2016: 87-105. Impreso.

Valbuena Briones, Ángel. "El concepto del hado en el teatro de Calderón". Bulletin hispanique. 63, 1/2 (1961): 48-53.

<www.persee.fr/doc/hispa_0007-4640_1961_num_63_1_3699> Web. 11 Feb. 2019.

Valbuena Briones, Ángel. Perspectiva crítica de los dramas de Calderón. Madrid: Rialp, 1965. Impreso.

Valbuena Prat, Ángel. Historia de la literatura española. Tomo II, Barcelona: Gustavo Gili, 1968. Impreso.

Vilanova, Antonio. "El tema del gran teatro del mundo", B.R.A.E. Letras de Barcelona, XXII, (1959): 153-188. <https://core.ac.uk/ download/pdf/38982252.pdf> Web. 01 Mar. 2019. 


\section{THE DESTINY IN THE WORKS OF LUCIUS ANNAEUS SENECA AND PEDRO CALDERÓN DE LA BARCA}

\section{Summary}

In this research of destiny in the works of Seneca and Calderón, we intend to compare attitudes of these authors faced with existential problems, still attracting attention of great thinkers. Showing the common points and discrepancies of the Roman philosopher from the $1^{\text {st }}$ century and the Spanish playwright from the $17^{\text {th }}$ century in regard to fate and other existential problems, the purpose of this analysis is to determine if Seneca influenced Calderón or it was just a coincidence. Our objective is based on the ethical approach to problems of both authors and a great interest for the practical philosophy of Seneca in the Spain of Golden Age. We noticed great similarities concerning fate, freedom and free will as well as the means that both sages use to protect themselves from the consequences of destiny. They concord that they have to submit to the fate voluntarily. They recognize the importance of gaining knowledge so as to distinguish between goods worldly or real and to know themselves. Both underline that a man, a rational creature, possessing will and freedom is responsible for his acts. Their religious attitudes are different. Seneca introduces Providence into his fatalistic determinism to justify the existence of evil happening unexpectedly to honorable men. Seneca is uncertain about soul's immortality or the image of his God. He lacks Calderón's faith in his Christian God. Contrary to Seneca, Calderón raises God above fate. His infinite love helps his believers repent and saves their soul. For Calderón, the only Fate is God. Seneca, with his moralizing advice obviously influenced Calderón, but it is difficult to specify if he was influenced directly or by other sources. In our research we applied comparative method.

Keywords: Calderón, Seneca, destiny, fate, free will. 